\title{
Clinical characteristics of re-hospitalized COVID-19 patients with recurrent positive SARS-CoV-2 RNA: a retrospective study
}

\author{
Lei Pan ${ }^{1} \cdot$ Runsheng Wang ${ }^{2} \cdot \mathrm{Na} \mathrm{Yu}^{3} \cdot \mathrm{Chao} \mathrm{Hu}^{2}$ • Junhong Yan ${ }^{4} \cdot \mathrm{Xiaomin}_{\mathrm{Zhang}^{5}}$ - Tao Wang ${ }^{1}$. Jungui Hao ${ }^{6}$.

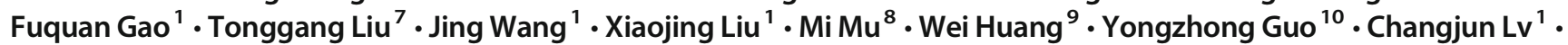 \\ Xiaozhi Wang ${ }^{1} \cdot$ Lei Tu $^{11} \cdot$ Kun Wan $^{12} \cdot$ Guogang Xu ${ }^{13}$
}

Received: 9 October 2020 / Accepted: 30 December 2020 / Published online: 15 January 2021

(C) The Author(s), under exclusive licence to Springer-Verlag GmbH, DE part of Springer Nature 2021

\begin{abstract}
At present, it has been noticed that some patients recovered from COVID-19 present a recurrent positive RNA test of SARSCoV-2 (severe acute respiratory syndrome coronavirus 2) after being discharged from hospitals. The purpose of the current study was to characterize the clinical features of re-hospitalized patients with recurrent SARS-CoV-2 positive results. From January 12 to April 1 of 2020, our retrospective study was conducted in China. The exposure history, baseline data, laboratory findings, therapeutic schedule, and clinical endpoints of the patients were collected. All the patients were followed until April 10, 2020. Among all COVID-19 patients included in the current study, there were 14 re-hospitalized patients due to recurrent positive tests of SARS-CoV-2 RNA. Fever (11 [78.6\%]), cough (10 [71.4\%]), and fatigue (7 [50.0\%]) were the most common symptoms on the patient's first admission, and less symptoms were found on their second admission. The average duration from the onset of symptoms to admission to hospital was found to be 8.4 days for the first admission and 2.6 days for the second admission $(P=$ 0.002). The average time from the detection of RNA (+) to hospitalization was 1.9 days for the first admission and 2.6 days for the second admission $(P=0.479)$, and the average time from RNA (+) to RNA ( - ) was 11.1 days for the first admission and 6.3 days for the second admission $(P=0.030)$. Moreover, the total time in hospital was 18.6 days for the first admission and 8.0 days for the second admission $(P=0.000)$. It may be necessary to increase the isolation observation time and RT-PCR tests should be timely performed on multiple samples as soon as possible.
\end{abstract}

Keywords SARS-CoV-2 $\cdot$ COVID-19 $\cdot$ Re-hospitalization $\cdot$ Management $\cdot$ Outcome

\section{Introduction}

On Mar 14, 2020, the newly discovered severe acute respiratory syndrome coronavirus 2 (SARS-CoV-2) was declared by

Lei Pan, Runsheng Wang, $\mathrm{Na} \mathrm{Yu,} \mathrm{Chao} \mathrm{Hu} \mathrm{contributed} \mathrm{equally} \mathrm{to} \mathrm{this}$ work. They are listed as co-first authors. Xiaozhi Wang, Lei Tu, Kun Wan and Guogang $\mathrm{Xu}$ are listed as co-corresponding authors.
Xiaozhi Wang
bzyxy3013@163.com
tulei_1985@126.com
Kun Wan
301wk@sina.com
Guogang Xu
guogang_xu@163.com

$\triangle$ Lei Tu

Extended author information available on the last page of the article the World Health Organization (WHO) that induced coronavirus disease 2019 (COVID-19), which resulted in the present worldwide pandemic. COVID-19 is spreading around the world and threatening global health [5, 8]. Tillett et al. used genome sequencing to show that one patient could be infected by SARS-CoV-2 in two different occasions and found that the second infection of this patient had more severe symptoms than that in the first infection [15], which shows that reinfection with SARS-CoV-2 may challenge the efficacy of vaccines [6]. However, Cento et al. believed that a recurrent positive test of SARS-CoV-2 RNA did not mean of a transmissible virus in vivo [1]. The symptomatic patients with COVID-19 are supposed to be the main source of outbreak, but asymptomatic infections may be a potential troubling occurrence in the near future $[10,12,20]$.

Asymptomatic infections were announced in the seventh edition of the guidelines from National Health Commission of China. In clinical practice, very few cured patients were detected 
with positive SARS-CoV-2 RNA even after discharging [7, 9, $18,19]$. A meta-analysis of 17 studies with 5182 COVID-19 patients reported a recurrence positive SARS-CoV-2 RNA rate of $12 \%$. They believed that the respiratory tract samples should be repeated nucleic acid tests in both the first and second months after recovery from COVID-19 [13]. Follow-up observation of the baseline characteristics of these patients and whether family members are infected with SARS-CoV-2 may help to develop management strategies in targeting these groups. Here, we reported 14 re-hospitalized patients due to a recurrent positive result of SARS-CoV-2 RNA. Further investigations of the clinical characteristics of such patients may contribute to the improvement of current criteria for release and reduction of recurrence rate.

\section{Materials and methods}

\section{Study design}

The study was performed in China from January 12 to April 1, 2020 and had been approved by the Ethics Committees of Huanggang Central Hospital (No. HGYY-2020-005) and Wuhan Union Hospital (No. 2020-0077-1). In total, 1350 patients with COVID-19 from the general wards and intensive care units (ICU) were initially enrolled in the current study.

The inclusion criteria were (1) diagnosis of COVID-19 was all confirmed by positive test of SARS-CoV-2 RNA from the throat swab or sputum samples according to WHO interim guidance; (2) criteria for all COVID-19 patients discharging from hospitals were based on the guidelines by National Health Commission of China: (i) normal temperature for at least 3 days, (ii) no obvious respiratory symptoms, (iii) significant absorption of lesions in chest computerized tomography (CT) scans, (iv) double check of negative SARS-CoV-2 RNA tests (sampling interval over 24h); (3) the patients were hospitalized no less than 2 times due to re-detectable positive SARS-CoV-2 RNA; (4) chest CT scans and blood tests were performed. Those patients who did not meet all of the criteria listed above were excluded from the current study.

\section{Data collection}

Each COVID-19 case report was carefully reviewed from electronic medical records. All the data were collected by two different co-authors independently. The exposure history, demographic data, baseline characteristics, laboratory data, therapeutic programs, and clinical endpoints, especially the RNA test of SARSCoV-2, were extracted. The results of viral RNA were based on the first positive and the first valid negative data (i.e., the first negative result before reaching the discharge standard). In the present study, samples by throat swabs were obtained from the patients at the time of admission, and during the time of home or hotel quarantine were tested by real-time reverse transcription PCR [4].

\section{Statistical analysis}

Continuous data were shown as means ( \pm standard deviation [SD]) or medians with interquartile range (IQR). Categorical data were described as percentages. All laboratory results were assessed if the measurements exceeded the normal level. A paired $t$ test was used for continuous data and chi-squared test was applied to compare count data. A two-tailed $P$ value less than 0.05 was selected as the cutoff value for statistical significance. SPSS version 20 (SPSS, Chicago, IL, USA) was used to conduct statistical analyses in the current study.

\section{Results}

\section{Baseline characteristics}

A total of 1350 COVID-19 patients were selected as the initial study population from January 12 to April 1, 2020. Only 20 cases of COVID-19 were re-detected with positive SARSCoV-2 RNA. Six patients who lack complete data were excluded. Finally, 14 cases met the inclusion criteria. The final follow-up was April 10, 2020.

Baseline characteristics of 14 patients on two admissions are summarized in Tables 1, 2, and Fig. 1. The average age of the patients was 44.4 years old ( $\mathrm{SD} \pm 15.0$ ), with 10 males and 4 females. According to the epidemiological history, 7 (50.0\%) patients remembered clearly about their history of exposure in the first admission and $14(100.0 \%)$ patients in the second admission. Fever (11 [78.6\%]), cough (10 [71.4\%]), and fatigue (7 [50.0\%]) were the most common symptoms, and digestive symptoms such as lack of appetite (4 [28.6\%]) and diarrhea (1 [7.1\%]) were reported on the first admission. However, except for one patient who had a cough, the remaining 13 patients had no symptoms on the second admission. Additionally, new lesions were not found in all patients undergoing chest CT on second admission. Meanwhile, most patients rarely had underlying comorbidities. On the first admission, there were 14 (100.0\%) patients receiving antiviral drugs including lopinavir/ ritonavir or arbidol, $11(78.57 \%)$ receiving Lianhua Qingwen, and $8(57.1 \%)$ receiving nebulized $\alpha$-interferon treatment. Similarly, $10(71.43 \%)$ patients on second hospitalization received antiviral treatment.

\section{RNA test outcomes of SARS-CoV-2}

The results of SARS-CoV-2 RNA are shown in Table 2 and Fig. 1. In detail, the average time from detection of RNA (+) to hospital admission was 1.9 days $(\mathrm{SD} \pm 1.6)$ for the first admission and 2.6 days $(\mathrm{SD} \pm 2.2)$ for the second admission $(P=$ 


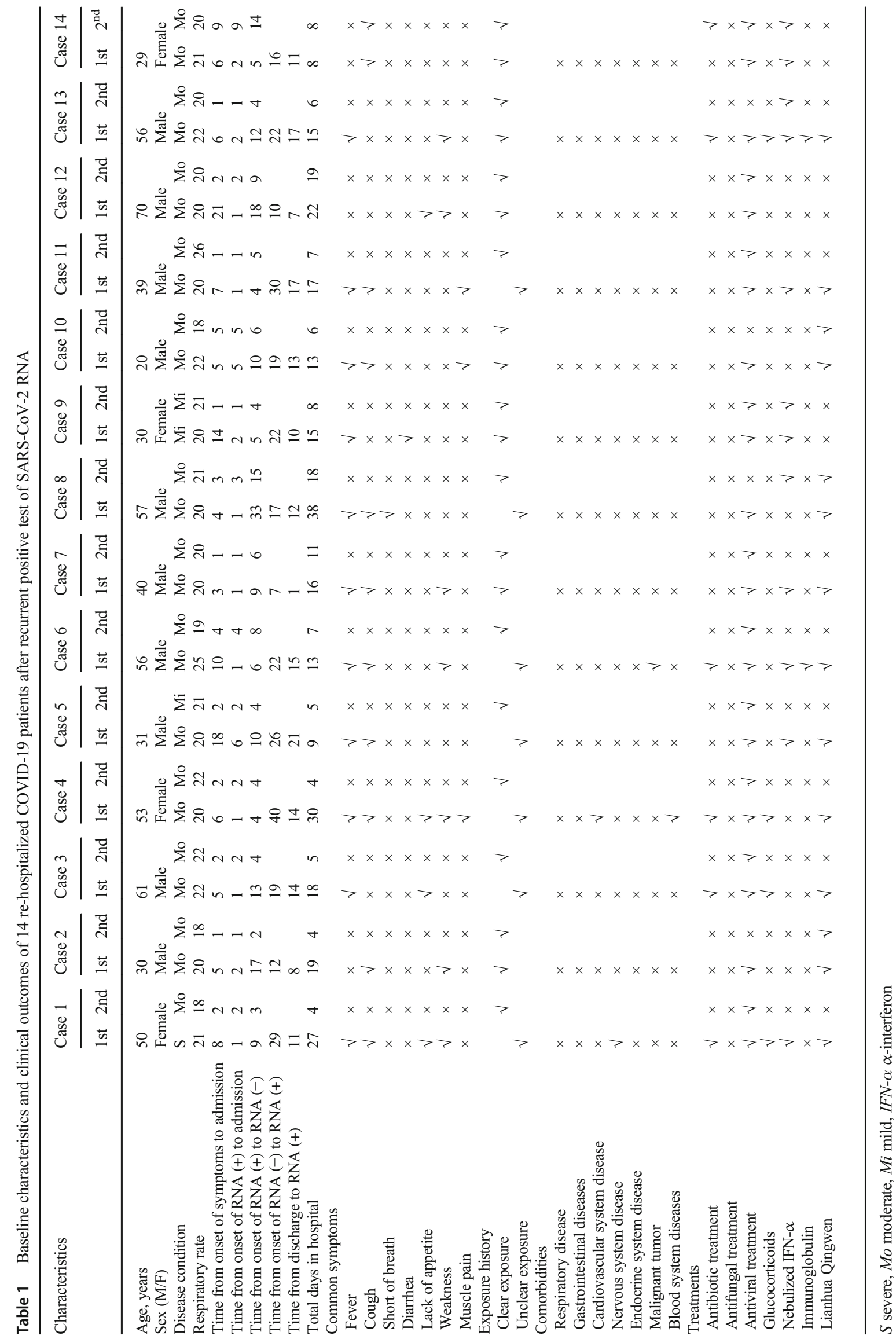


Table 2 Clinical outcomes of COVID-19 patients between two admissions

\begin{tabular}{|c|c|c|c|}
\hline \multirow[t]{2}{*}{ Characteristics } & \multicolumn{2}{|l|}{ All patients $(n=14)$} & \multirow[t]{2}{*}{$P$ value } \\
\hline & First admission $(n=14)$ & Second admission $(n=14)$ & \\
\hline Age, years [mean $(\mathrm{SD})]$ & $44.4 \pm 15.0$ & & / \\
\hline $\operatorname{Sex}(\mathrm{M} / \mathrm{F})$ & $(10 / 4)$ & & \\
\hline Respiratory rate & $20.9 \pm 1.4$ & $20.4 \pm 2.1$ & 0.530 \\
\hline Days from onset of symptoms to admission & $8.4 \pm 5.5$ & $2.6 \pm 2.2$ & 0.002 \\
\hline Days from onset of RNA (+) to admission & $1.9 \pm 1.6$ & $2.6 \pm 2.2$ & 0.479 \\
\hline Days from onset of RNA (+) to RNA (-) & $11.1 \pm 7.7$ & $6.3 \pm 4.0$ & 0.030 \\
\hline Days from onset of RNA (-) to RNA (+) & $20.8 \pm 8.7$ & & / \\
\hline Days from discharge to RNA (+) & $12.2 \pm 4.9$ & & / \\
\hline Total days in hospital & $18.6 \pm 8.3$ & $8.0 \pm 4.9$ & 0.000 \\
\hline \multicolumn{4}{|l|}{ Common symptoms } \\
\hline Fever & $11(78.6 \%)$ & $0(0.0 \%)$ & 0.003 \\
\hline Cough & $10(71.4 \%)$ & $1(7.1 \%)$ & 0.008 \\
\hline Short of breath & $1(7.1 \%)$ & $0(0.0 \%)$ & 0.999 \\
\hline Diarrhea & $1(7.1 \%)$ & $0(0.0 \%)$ & 0.999 \\
\hline Lack of appetite & $4(28.6 \%)$ & $0(0.0 \%)$ & 0.134 \\
\hline Fatigue & $7(50.0 \%)$ & $0(0.0 \%)$ & 0.023 \\
\hline Muscle pain & $3(21.4 \%)$ & $0(0.0 \%)$ & 0.249 \\
\hline \multicolumn{4}{|l|}{ Epidemiological history } \\
\hline Clear contact history & $7(50.0 \%)$ & $14(100.0 \%)$ & 0.023 \\
\hline Unclear contact history & $7(50.0 \%)$ & $0(0.0 \%)$ & 0.023 \\
\hline \multicolumn{4}{|l|}{ Medical treatment after admission } \\
\hline Antibiotic treatment & $5(35.7 \%)$ & $1(7.1 \%)$ & 0.221 \\
\hline Antifungal treatment & $0(0.0 \%)$ & $0(0.0 \%)$ & \\
\hline Antiviral treatment & $14(100.0 \%)$ & $10(71.4 \%)$ & 0.134 \\
\hline Glucocorticoids & $4(28.6 \%)$ & $0(0.0 \%)$ & 0.134 \\
\hline Nebulized $\alpha$-interferon treatment & $8(57.1 \%)$ & $4(28.6 \%)$ & 0.134 \\
\hline Intravenous immunoglobulin therapy & $2(14.3 \%)$ & $0(0.0 \%)$ & 0.480 \\
\hline Lianhua Qingwen & $11(78.6 \%)$ & $3(21.4 \%)$ & 0.013 \\
\hline
\end{tabular}

0.479). The average time from RNA (+) to RNA (-) was 11.1 days $(\mathrm{SD} \pm 7.7)$ for the first admission and 6.3 days $(\mathrm{SD} \pm 4.0)$ for the second admission $(P=0.030)$. The average time from onset of RNA (-) to RNA (+) was 20.8 days (SD \pm 8.7$)$ and the range of days from onset of RNA $(-)$ to RNA $(+)$ were 7 to 40 days for these patients. The average time from discharge to RNA (+) was 12.2 days ( $\mathrm{SD} \pm 4.9)$ and the days ranged from 1 to 21 days. Of the 14 cases, 4 (28.6\%) patients had more than 14 days from discharge until recurrent positive SARS-CoV-2 RNA. Moreover, the average time from onset of symptoms to admission was 8.4 days ( $\mathrm{SD} \pm 5.5$ ) for the first admission and 2.6 days $(\mathrm{SD} \pm 2.2)$ for the second admission $(P=0.002)$. Additionally, the total time in hospital was 18.6 days (SD \pm 8.3) for the first admission and 8.0 days $(\mathrm{SD} \pm 4.9)$ for the second admission $(P=0.000)$.

\section{Laboratory findings}

Table 3 shows the details of laboratory data for two admitted in patients with COVID-19. White blood cell counts were 4.4 $\times 10^{9} / \mathrm{L}(\mathrm{SD} \pm 1.8)$ on the first admission and $5.8 \times 10^{9} / \mathrm{L}(\mathrm{SD}$ $\pm 1.4)$ on the second admission $(P=0.013)$, which may be a result of the increased lymphocyte and monocyte on the second admission $(P=0.000,0.014)$. Platelet counts were 175.4 $\times 10^{9} / \mathrm{L}(\mathrm{SD} \pm 42.6)$ on the first admission and $207.6 \times 10^{9} / \mathrm{L}$ $(\mathrm{SD} \pm 46.7)$ on the second admission $(P=0.016)$. Moreover, several endpoints including prothrombin time, activated partial thromboplastin time, aspartate aminotransferase, and creatinine were significantly lower on the second admission than on the first admission (all $P<0.05$ ). However, the significance of these changes is still unclear. There were no significant differences in other lab data for the second admissions.

\section{Discussion}

Fourteen COVID-19 patients with recurrent positive test of viral RNA after hospital discharging or termination of quarantine in Hubei, China (without clinical symptoms and radiological abnormalities and with two consecutive negative viral RNA test results over $24 \mathrm{~h}$ interval), were characterized in the present study. All these patients had positive test in 7-40 days since RNA (-), without any aggravation on symptoms and chest CT. Despite the fact that the incidence of recurrent SARS-CoV-2 positive results in recovered patients is low, this group of patients should be tested timely for many times.

Till now, the asymptomatic patients with SARS-CoV-2 infection could be a new source of transmission, which would bring some new infectious disease prevention and control issues $[11,14]$. In general, these recurrent cases are characterized as asymptomatic viral carriers, but they are different from the "true" first diagnostic asymptomatic patient. These 
Case 1 Age. 50 o

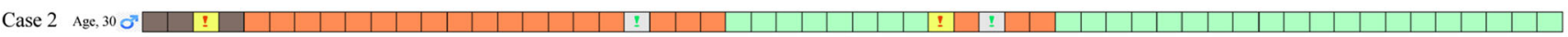
Case 3 Age, 61 o'

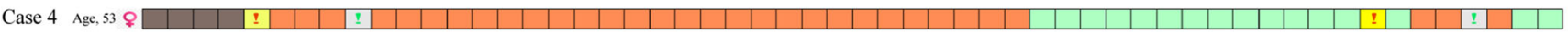
Case 5 Age, 31 o'

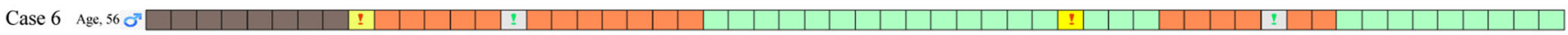

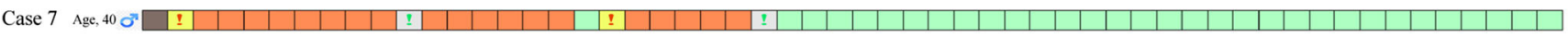

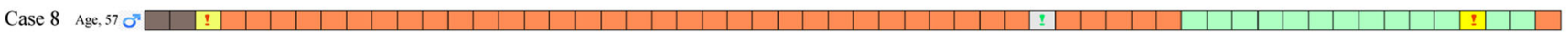

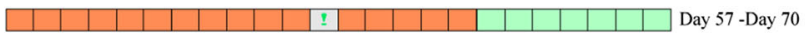

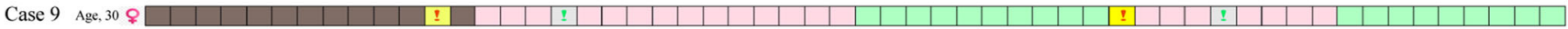

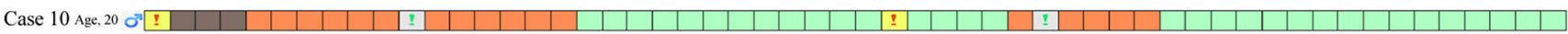

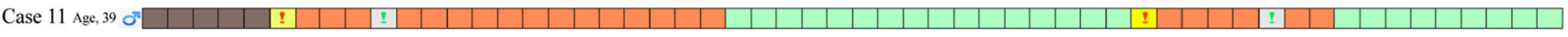
Case 12 Age, 70 ơ

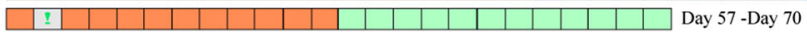

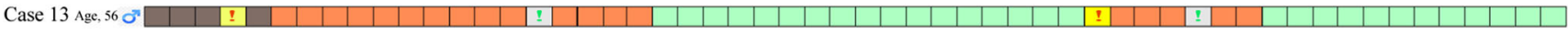
Case 14 Age, 29 \%

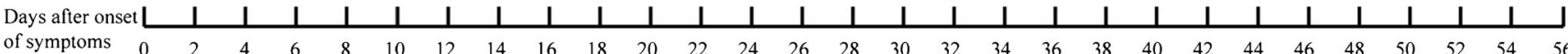
! RNA(+) Stay at home with symptoms (1) RNA (-) Hospital discharge and medical isolation

\begin{tabular}{c} 
Admitted to the hospital \\
\hline Mild $\quad \square$ Moderate $\square$ Servere
\end{tabular}

Fig. 1 The admission and discharge history of 14 re-hospitalized COVID-19 patients after recurrent positive SARS-CoV-2 RNA

Table 3 Laboratory findings of patients with COVID-19 between two admissions

\begin{tabular}{|c|c|c|c|}
\hline \multirow[t]{2}{*}{ Characteristics } & \multicolumn{2}{|l|}{ All patients $(n=14)$} & \multirow[t]{2}{*}{$P$ value } \\
\hline & First admission $(n=14)$ & Second admission $(n=14)$ & \\
\hline White blood cell count, $\times 10^{9} / \mathrm{L}$ & $4.4 \pm 1.8$ & $5.8 \pm 1.4$ & 0.013 \\
\hline Neutrophil count, $\times 10^{9} / \mathrm{L}$ & $2.9 \pm 1.3$ & $3.6 \pm 1.0$ & 0.119 \\
\hline Red blood cell count, $\times 10^{9} / \mathrm{L}$ & $4.6 \pm 0.5$ & $4.3 \pm 0.7$ & 0.103 \\
\hline Hemoglobin, $\mathrm{g} / \mathrm{L}$ & $137.9 \pm 16.1$ & $134.1 \pm 22.3$ & 0.318 \\
\hline Neutrophil ratio, $\%$ & $65.1 \pm 9.8$ & $61.2 \pm 6.0$ & 0.214 \\
\hline Lymphocyte count, $\times 10^{9} / \mathrm{L}$ & $1.1 \pm 0.5$ & $1.6 \pm 0.4$ & 0.000 \\
\hline Lymphocyte ratio, \% & $26.3 \pm 8.3$ & $28.5 \pm 5.1$ & 0.353 \\
\hline Monocyte count, $\times 10^{9} / \mathrm{L}$ & $0.3 \pm 0.1$ & $0.4 \pm 0.2$ & 0.014 \\
\hline Platelet count, $\times 10^{9} / \mathrm{L}$ & $175.4 \pm 42.6$ & $207.6 \pm 46.7$ & 0.016 \\
\hline Prothrombin time, $\mathrm{s}$ & $12.1 \pm 1.0$ & $11.2 \pm 1.2$ & 0.003 \\
\hline Prothrombin activity, $\%$ & $109.3 \pm 22.2$ & $109.4 \pm 18.1$ & 0.653 \\
\hline Activated partial thromboplastin time, $\mathrm{s}$ & $32.8 \pm 4.7$ & $31.0 \pm 2.8$ & 0.049 \\
\hline Fibrinogen, $\mathrm{g} / \mathrm{L}$ & $4.1 \pm 1.3$ & $3.5 \pm 0.8$ & 0.098 \\
\hline Alanine aminotransferase, $\mathrm{U} / \mathrm{L}$ & $25.8 \pm 22.7$ & $33.79 \pm 25.6$ & 0.162 \\
\hline Aspartate aminotransferase, $\mathrm{U} / \mathrm{L}$ & $25.7 \pm 9.7$ & $21.8 \pm 9.6$ & 0.029 \\
\hline Total bilirubin, $\mathrm{mmol} / \mathrm{L}$ & $14.3 \pm 9.1$ & $16.2 \pm 9.4$ & 0.352 \\
\hline Albumin, g/L & $41.1 \pm 5.7$ & $41.4 \pm 3.8$ & 0.930 \\
\hline Blood nitrogen, mmol/L & $4.4 \pm 1.6$ & $4.6 \pm 0.9$ & 0.626 \\
\hline Creatinine, $\mu \mathrm{mol} / \mathrm{L}$ & $83.2 \pm 19.8$ & $68.6 \pm 13.3$ & 0.014 \\
\hline Fasting blood glucose, $\mathrm{mmol} / \mathrm{L}$ & $5.2 \pm 0.9$ & $5.2 \pm 0.6$ & 0.946 \\
\hline
\end{tabular}


patients were previously diagnosed with COVID-19 and were discharged after standard treatment to meet the criteria for discharging. Moreover, it is important to note that people who had close contact with these recurrent cases were not found to have signs of COVID-19 infection. From this point of view, the management strategy for these recurrence cases is mainly isolation and observation. Our results suggested that antiviral therapy may not be a necessary treatment and that personalized treatment should be adopted for COVID-19 patients with recurrent positive SARS-CoV-2 RNA.

The underlying mechanisms of fluctuated SARS-CoV-2 RNA results are worth investigating. According to our results, all the 14 COVID-19 patients reported here with recurrent positive test of SARS-CoV-2 RNA had very clear history of a known exposure before their second admission and were related to the re-infection [21], which may explain the recurrence. Besides, real time-PCR assays with respiratory samples are considered as the reference standard for the diagnosis of COVID-19 [2]. As angiotensin converting enzyme-2 (ACE-2) is the host cell receptor for SARS-CoV-2 and is more easily spread in the lungs, the SARS-CoV-2 results may be false negative in nose or throat swab samples $[3,17]$, due to the lower viral load in these sites. Therefore, point-of-care technologies and serologic immunoassays may be a useful detection method [2]. Moreover, the proficiency of the operators and the accuracy of the kits are also important factors affecting the SARS-CoV-2 RNA results and can result in a falsenegative RT-PCR result for detection of the virus [16]. What is more, the interval between two negative RT-PCR tests may not be sufficient to evaluate the degree of virus clearance. Before the second infection, further investigation is necessary to clarify pre-existing immune responses and viral load [6]. Viral load should be given more consideration as it is the most reliable method in determining whether it is safe for the patient to return to society [1].

In view of the possibility that the RT-PCR test results of the patients under the current criteria for hospital release from quarantine may convert to positive, some measures can be put in place to improve the current criteria and reduce the recurrence rate. Firstly, all the discharged patients are currently suggested to self-quarantine in their houses for 14 days according to China's National Health Commission. However, our results indicated that the range of days from discharge to RNA (+) were 1 to 21 days, and $4(28.6 \%)$ patients had more than 14 days from discharge to recurrent positive SARS-CoV-2 RNA. Mao et al. found that after a 14-day isolation, asymptomatic COVID-19 patients could be a source of viral transmission and proposes a challenge to selfquarantine [12]. Therefore, we believe that it may be more appropriate to recommend 3 weeks of self-quarantine for COVID-19 patients after discharge, who were performed RT-PCR test as soon as possible. Secondly, a longer interval, such as $48 \mathrm{~h}$, between two consecutive negative results in the criteria for discharging from hospitals or the termination of the quarantine may be feasible to ensure that the patients to be discharged are not contagious and are less likely to have a recurrent positive SARS-CoV-2 RNA. Additionally, some laboratory examinations such as the absolute white blood cell as well as lymphocyte counts could be combined with the RTPCR results as the criteria for hospital discharge to assure that the patients have completely recovered. Moreover, as SARSCoV-2 RNA could be detected from sputum, throat swab, blood, or stool swab samples, multiple tests of different samples can be helpful in improving sensitivity. The test from bronchoalveolar lavage fluid specimen could be more reliable; however, a higher risk of exposure might occur. Finally, there is still no strong evidence of the contagious period of SARS$\mathrm{CoV}-2$ and the sample size was limited, and further studies will be needed to reduce the recurrence rate.

Limitations in the current study should be noted. Firstly, several missing data or even failure to follow-up can affect the accuracy of a patient's identification. Therefore, selection bias is hard to avoid and might occur for the retrospective study, and further prospective studies are needed. Second, our results were mainly based on two hospitals, and a large-scale multicenter study will be needed to pay more attention to the interesting topic in future. Last but not least, because of the lack of genome sequencing, we are unable to confirm that the positive test results in the re-hospitalized patients were due to the relapse of the same viral strain or reinfection with a new strain. In future research, we will try genome sequencing to help us identify whether the disease is due to reinfection or a relapse.

\section{Conclusion}

In conclusion, the incidence of recurrent positive SARSCoV-2 RNA test in the patients with COVID-19 after discharge is relatively low and these patients have virtually no symptoms. However, considering the possible potential infectivity, we believe that the current national guidelines may need to be further revised, especially those with recurrent positive results of SARS-CoV-2 RNA test. Furthermore, it could be particularly necessary to increase the isolation observation time and RT-PCR tests should be timely performed on multiple samples as soon as possible. Additionally, we should pay more attention to genome sequencing in order to identify whether the patient is reinfected or relapsed. Considering the patients' underlying disease, personalized treatment should be taken to treat recurrent positive patients with COVID-19.

Acknowledgments We thank all the patients included in the current study. All co-authors sincerely appreciate all the medical staffs who assisted Hubei and fought in the front line. We also thank Troy Gharibani (University of Maryland, USA) for improving the manuscript. 
Authors' contributions LP, LT, GX, KW, and XW conceptualized the manuscript and edited subsequent versions. LP, RW, NY, and $\mathrm{CH}$ wrote the first draft. JY, XZ, TW, JH, FG, TL, JW, XL, MM, and WH collected and analyzed data. YG and CL contributed ideas on the texts. All authors approved the final manuscript.

Funding This work was supported by Technology Plan Project of Binzhou Medical University (CN, BY2017KJ30), Health and Family Planning Commission of Shandong Province (CN, 2017WS366), and National Natural Science Foundation of China (CN, 81700490).

Data availability All data generated or analyzed during this study are included in this published article [and its tables and figures].

\section{Compliance with ethical standards}

Conflict of interest The authors declare that they have no conflict of interest.

Ethics approval The study had been approved by the Ethics Committees of Huanggang Central Hospital (No. HGYY-2020-005) and Wuhan Union Hospital (No. 2020-0077-1).

\section{Consent to participate Exemption.}

Consent for publication The participant has consented to the submission of this article to the journal. We confirm that the manuscript, or part of it, has neither been published nor is currently under consideration for publication. This work and the manuscript were approved by all coauthors.

Code availability SPSS version 20 (SPSS, Chicago, IL, USA).

\section{References}

1. Cento V, Colagrossi L, Nava A, Lamberti A, Senatore S, Travi G et al (2020) Persistent positivity and fluctuations of SARS-CoV-2 RNA in clinically-recovered COVID-19 patients. J Infect 81:e90e92. https://doi.org/10.1016/j.jinf.2020.06.024

2. Cheng MP, Papenburg J, Desjardins M, Kanjilal S, Quach C, Libman $M$ et al (2020) Diagnostic testing for severe acute respiratory syndrome-related coronavirus-2: a narrative review. Ann Intern Med. https://doi.org/10.7326/M20-1301

3. Feng H, Liu Y, Lv M, Zhong J (2020) A case report of COVID-19 with false negative RT-PCR test: necessity of chest CT. Jpn J Radiol. https://doi.org/10.1007/s11604-020-00967-9

4. Huang C, Wang Y, Li X, Ren L, Zhao J, Hu Y et al (2020) Clinical features of patients infected with 2019 novel coronavirus in Wuhan, China. Lancet 395:497-506. https://doi.org/10.1016/S01406736(20)30183-5

5. Hui DS, E, I. A., Madani, T. A., Ntoumi, F., Kock, R., Dar, O., et al. (2020) The continuing 2019-nCoV epidemic threat of novel coronaviruses to global health - the latest 2019 novel coronavirus outbreak in Wuhan, China. Int J Infect Dis 91:264-266. https://doi. org/10.1016/j.ijid.2020.01.009
6. Iwasaki A (2020) What reinfections mean for COVID-19. Lancet Infect Dis. https://doi.org/10.1016/S1473-3099(20)30783-0

7. Jiang DM (2020) Recurrent PCR positivity after hospital discharge of people with coronavirus disease 2019 (COVID-19). J Infect. https://doi.org/10.1016/j.jinf.2020.03.024

8. Khot WY, Nadkar MY (2020) The 2019 novel coronavirus outbreak - a global threat. J Assoc Physicians India 68:67-71

9. Lan L, Xu D, Ye G, Xia C, Wang S, Li Y et al (2020) Positive RTPCR test results in patients recovered from COVID-19. JAMA. https://doi.org/10.1001/jama.2020.2783

10. Li C, Ji F, Wang L, Wang L, Hao J, Dai M et al (2020) Asymptomatic and human-to-human transmission of SARS-CoV2 in a 2-family cluster, Xuzhou. China. Emerg Infect Dis 26. https://doi.org/10.3201/eid2607.200718

11. Ling Z, Xu X, Gan Q, Zhang L, Luo L, Tang X et al (2020) Asymptomatic SARS-CoV-2 infected patients with persistent negative CT findings. Eur J Radiol 126:108956. https://doi.org/10. 1016/j.ejrad.2020.108956

12. Mao ZQ, Wan R, He LY, Hu YC, Chen W (2020) The enlightenment from two cases of asymptomatic infection with SARS-CoV-2: is it safe after 14 days of isolation? Int J Infect Dis. https://doi.org/ 10.1016/j.ijid.2020.03.041

13. Mattiuzzi C, Henry BM, Sanchis-Gomar F, Lippi G (2020) SARSCoV-2 recurrent RNA positivity after recovering from coronavirus disease 2019 (COVID-19): a meta-analysis. Acta Biomed 91: e2020014. https://doi.org/10.23750/abm.v91i3.10303

14. Qian G, Yang N, Ma AHY, Wang L, Li G, Chen X et al (2020) A COVID-19 Transmission within a family cluster by presymptomatic infectors in China. Clin Infect Dis. https://doi.org/10.1093/cid/ ciaa316

15. Tillett RL, Sevinsky JR, Hartley PD, Kerwin H, Crawford N, Gorzalski A et al (2020) Genomic evidence for reinfection with SARS-CoV-2: a case study. Lancet Infect Dis. https://doi.org/10. 1016/S1473-3099(20)30764-7

16. Xiao AT, Tong YX, Zhang S (2020) False-negative of RT-PCR and prolonged nucleic acid conversion in COVID-19: rather than recurrence. J Med Virol. https://doi.org/10.1002/jmv.25855

17. Xie C, Lu J, Wu D, Zhang L, Zhao H, Rao B et al (2020) False negative rate of COVID-19 is eliminated by using nasal swab test. Travel Med Infect Dis 101668. https://doi.org/10.1016/j.tmaid. 2020.101668

18. Xu Y, Li X, Zhu B, Liang H, Fang C, Gong Y et al (2020) Characteristics of pediatric SARS-CoV-2 infection and potential evidence for persistent fecal viral shedding. Nat Med 26:502-505. https://doi.org/10.1038/s41591-020-0817-4

19. Yuan J, Kou S, Liang Y, Zeng J, Pan Y, Liu L (2020) PCR assays turned positive in 25 discharged COVID-19 patients. Clin Infect Dis. https://doi.org/10.1093/cid/ciaa398

20. Zhang J, Tian S, Lou J, Chen Y (2020) Familial cluster of COVID19 infection from an asymptomatic. Crit Care 24:119. https://doi. org/10.1186/s13054-020-2817-7

21. Zhou L, Liu K, Liu HG (2020) Cause analysis and treatment strategies of "recurrence" with novel coronavirus pneumonia (covid-19) patients after discharge from hospital. Zhonghua Jie $\mathrm{He} \mathrm{He} \mathrm{Hu} \mathrm{Xi}$ Za Zhi 43:E028. https://doi.org/10.3760/cma.j.cn11214720200229-00219

Publisher's note Springer Nature remains neutral with regard to jurisdictional claims in published maps and institutional affiliations. 


\section{Affiliations}

Lei Pan ${ }^{1} \cdot$ Runsheng Wang ${ }^{2} \cdot \mathrm{Na} \mathrm{Yu}^{3} \cdot \mathrm{Chao} \mathrm{Hu}^{2} \cdot$ Junhong $\mathrm{Yan}^{4} \cdot \mathrm{Xiaomin}_{\mathrm{Zhang}}{ }^{5} \cdot \mathrm{Tao}$ Wang ${ }^{1} \cdot$ Jungui Hao $^{6}$.

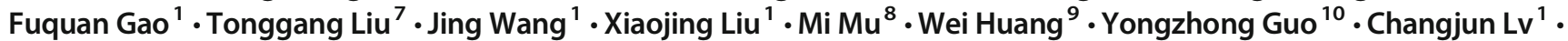
Xiaozhi Wang ${ }^{1} \cdot$ Lei Tu $^{11} \cdot$ Kun Wan ${ }^{12} \cdot$ Guogang Xu ${ }^{13}$

1 Department of Respiratory and Critical Care Medicine, Binzhou Medical University Hospital, Binzhou, China

2 Department of Respiratory Medicine, The Second Medical Center \& National Clinical Research Center for Geriatric Diseases, Medical College of PLA, Chinese PLA General Hospital, Beijing, China

3 Department of Gynecology, Shandong Provincial Third Hospital, Jinan, China

4 Department of Ultrasound, Binzhou Medical University Hospital, Binzhou, China

5 Department of Nephrology, Binzhou Medical University Hospital, Binzhou, China

6 Department of Infection Diseases, The Affiliated Hospital of Xuzhou Medical University, Xuzhou, China

7 Department of Infectious Diseases, Binzhou Medical University Hospital, Binzhou, China
8 Department of Disease Prevention and Control, The Second Medical Center \& National Clinical Research Center for Geriatric Diseases, Chinese PLA General Hospital, Beijing, China

9 Department of Infection Diseases, Huanggang Central Hospital, Huanggang, China

10 Department of Respiratory Medicine, Xuzhou Central Hospital, The Xuzhou School of Clinical Medicine of Nanjing Medical University, Xuzhou Clinical School of Xuzhou Medical University, Xuzhou, China

11 Division of Gastroenterology, Union Hospital, Tongji Medical College, Huazhong University of Science and Technology, Wuhan, China

12 Medical Supplies Center, Chinese PLA General Hospital, Beijing, China

13 The Second Medical Center \& National Clinical Research Center for Geriatric Diseases, Chinese PLA General Hospital, Beijing, China 